\title{
Phthiriasis palpebrarum: A case of eyelash infestation with Pthirus pubis
}

\author{
NA WU ${ }^{1,2}$, HONG ZHANG ${ }^{1}$ and FENG YUAN SUN ${ }^{1}$ \\ ${ }^{1}$ Department of Ophthalmology, Tianjin Medical University Eye Hospital, Tianjin 300384; \\ ${ }^{2}$ Department of Ophthalmology, Tianjin First Center Hospital, Tianjin 300192, P.R. China
}

Received September 22, 2015; Accepted December 12, 2016

DOI: $10.3892 / \mathrm{etm} .2017 .4187$

\begin{abstract}
Phthiriasis palpebrarum is a rare type of eyelid infestation. In the present study, a 63-year-old woman presented with a case of phthiriasis palpebrarum, which was initially misdiagnosed as anterior blepharitis. The patient had a 2-month history of repeated episodes of itching and burning sensations and moderate pain in both eyes that were not improved by antibiotic and corticosteroid eye drops. Slit lamp examination revealed lice and nits anchored to the eyelashes. All eyelashes were removed from the base along with lice and nits. The patient recovered fully within 2 weeks with no further management, and no evidence of lice or nits was found at the follow up. In conclusion, the findings of the present study suggests that patients presenting with itching of the eyelids and with clinical findings resembling seborrhea accumulation on the eyelashes should be carefully examined by prolonged observation with a slit lamp.
\end{abstract}

\section{Introduction}

Phthiriasis palpebrarum is a rare eyelid infestation caused by Phthiriasis pubis, commonly known as crab lice (1). Although their primary habitat is pubic hair, these lice are often found on the hair of the abdomen, thighs and the axilla, and occasionally they may invade the eyebrows and eyelashes (2). Lice may be transferred from one hair-bearing area to another, and any hair-bearing area may become infested (3). Sexual contact and parent-child interactions are the most typical routes of infestation and transfer occurs more often in this manner than through shared towels, sheets or clothes (4). Phthiriasis pubis infestation affects $1-2 \%$ of the human population worldwide (5) and is generally associated with poor hygiene and overcrowding (6). Infestations are most prevalent in sexually

Correspondence to: Professor Feng Yuan Sun, Department of Ophthalmology, Tianjin Medical University Eye Hospital, 251 Fukang Road, Tianjin 300384, P.R. China

E-mail: eyesunfy@126.com

Key words: phthiriasis palpebrarum, blepharitis, Pthirus pubis, ectoparasitic infestation active patients from 15 to 45 years old (7). In the present study, a case of lateral phthiriasis palpebrarum is reported. The patient provided written informed consent with regard to her data and images being included in the present case report.

\section{Case report}

A 63-year-old woman visited the Department of Ophthalmology, Tianjin First Center Hospital (Tianjin, China) on June 17, 2015, presenting with a 2-month history of repeated episodes of itching and burning sensations and moderate pain in both eyes. The patient had visited another hospital 1 month previously, where a diagnosis of common anterior blepharitis was made and she was prescribed a combination of Levofloxacin antibiotic eye drops and corticosteroid eye drops; however, her symptoms had not improved. On examination, corrected visual acuity was observed to be 20/20 in both eyes and intraocular pressure was $14 \mathrm{mmHg}$ in the right eye and $13 \mathrm{mmHg}$ in the left eye. A slit lamp examination was performed, which revealed $>10$ adult crab-like lice, and multiple red pinpoint excretions (Fig. 1). Mild hyperemia and excoriation was observed at the outer margin of the left upper eyelid, and brownish scales, which are indicative of louse feces, were present in the upper eyelashes (Fig. 2). A number of small, translucent oval eggs (nits) were observed adhering to the eyelashes and eyelids of the patient (Fig. 3) and moving lice were hanging from the eyelashes (Fig. 4). Some eyelashes, lice and nits were removed mechanically using flat tweezers. It is very difficult to grip the body of the louse firmly when using flat tweezers, because its head can be deep within the hair follicles. Force is required to extract the louse to ensure that the head is extracted from the follicle, at which time red dots are observed to appear on the skin of the eyelid. An eye examination revealed light conjunctival congestion, transparent cornea, normal transparent lens and no obvious abnormalities in the fundus. Parasitic bodies were sent for parasitological microscopic examination, which confirmed the primary diagnosis of Phthiriasis pubis infestation of the eyelashes. The patient stated that she had no previous infestations and no history of sexually transmitted diseases (STDs). She was referred to the Skin/STD Clinic of the Tianjin First Center Hospital for further evaluation and returned for a follow-up 2 weeks later. At the follow-up examination, the patient's symptoms had subsided completely. The patient was given advice on how to 
avoid future infestations, such as personal hygiene improvements and avoidance of close contact.

\section{Discussion}

Phthiriasis palpebrarum is characterized by infestation of the eyelashes with Pthirus pubis, which is classed as an STD (8). Approximately $30 \%$ of cases are associated with another STD $(9,10)$. Phthiriasis palpebrarum is uncommon in developed countries and typically presents in patients with poor personal hygiene (11). It is easily overlooked as the symptoms are similar to those of blepharoconjunctivitis and Pthirus pubis is primarily adapted to living in pubic hair (12). In heavy infestations, lice are found in the hair of the axilla, chest, eyebrows and eyelashes (13-15). Phthiriasis palpebrarum is also occasionally misdiagnosed as common blepharitis (16). Clinically, this disease is typically not considered, in particular when ocular symptoms are not obvious (17). To avoid this, it is recommended that eyelids and eyelashes are carefully examined by slit lamp to avoid misdiagnosis (18).

Pthirus pubis belongs to the phylum Arthropoda, the class Insecta and the order Phthiraptera. Two other subspecies of lice known to infest humans are Pediculus humanus capitis (head louse) and Pediculus humanus corporis (body louse) (19). Adult pubic lice are typically $1-2 \mathrm{~mm}$ in size and wingless with a broad, flat translucent body through which freshly ingested blood may be observed. The body is crab-like and divided into the head, thorax and abdomen, with three pairs of short, stout legs and powerful claws, which enable them to grasp hair shafts tightly (20).

Patients with phthiriasis palpebrarum typically present with palpebral pruritus, conjunctival inflammation, and occasionally preauricular lymphadenopathy due to secondary infection at the site of the louse bites (14). There are multiple treatment options available, including mechanical removal with forceps, trimming of the eyelashes, fluorescein eye drops $20 \%$, physostigmine $25 \%$, yellow mercuric oxide ointment $1 \%$, pilocarpine gel and oral ivermectin $(11,12,14)$. Phthiriasis palpebrarum may also be treated via argon laser therapy or cryotherapy (21). Mechanical removal has been demonstrated to be effective in treating the disease and preventing recurrence (22). In the present study, mechanical removal of lice and eggs was performed successfully. Ngai et al (23) suggested that clothing, towels and bedding used by the patient should be washed at $\geq 50^{\circ} \mathrm{C}$ within 2-3 days of treatment and dried on the hot cycle for 5-10 min. Pthirus pubis are only able to travel short distances from the point of first contact and die within 24-48 $\mathrm{h}$ if removed from their hosts (24-26). Due to the ease of transference, if the parasite is detected in one patient then all members of the household should be examined. In the present study, all family members were evaluated and did not require treatment.

In conclusion, the findings of the present study demonstrate the importance of a correct diagnosis due to the ease with which phthiriasis palpebrarum may be confused with blepharitis. As a result, it is suggested that eyelids and eyelashes should be carefully examined by slit lamp to avoid misdiagnosis in cases where blepharitis is considered. The present study also supports systemic treatment and it may be suggested that patients who present with phthiriasis

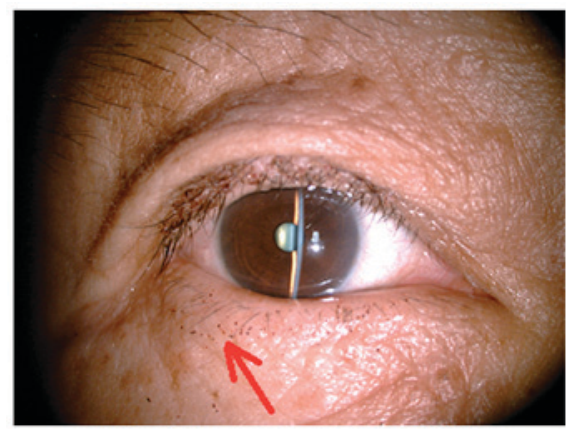

Figure 1. Slit lamp examination. Red arrow indicates multiple red pinpoint excretions.

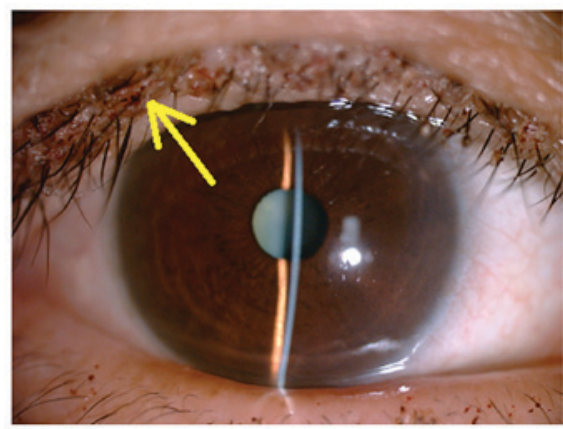

Figure 2. Slit lamp examination. Yellow arrow indicates mild hyperemia and excoriation of the outer margin of the left upper lid and brownish scales on the upper eyelashes.

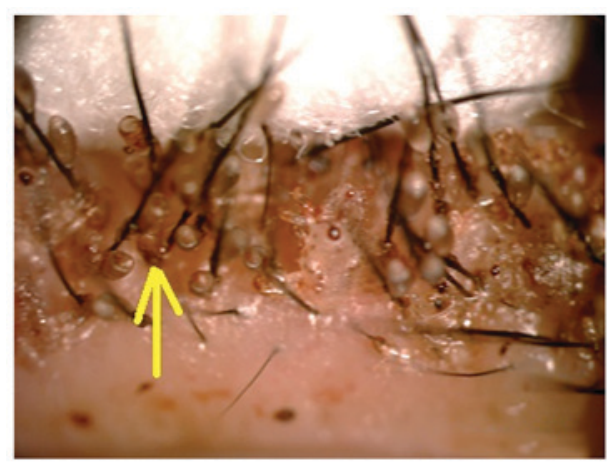

Figure 3. Slit lamp examination. Yellow arrow indicates multiple nits anchored on the upper eyelashes.

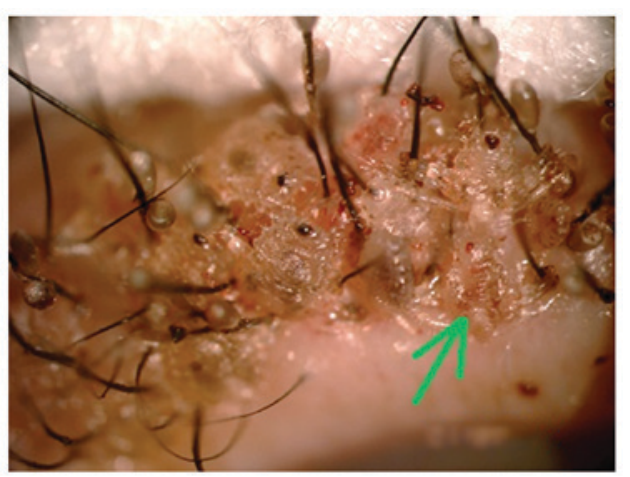

Figure 4. Slit lamp examination. Green arrow indicates ectoparasite and bloody crusts at the base of the eyelashes with nits localized in the middle area of the lashes. 
palpebrarum should undergo diagnostic tests for other STDs. Mechanical removal is the most effective treatment option for phthiriasis palpebrarum; however, follow-up examinations to detect any residual lice or nits are necessary.

\section{References}

1. Baskan C, Duman R, Balci M and Ozdogan S: A rare cause of blepharoconjunctivitis: Phthiriasis palpebrarum. Niger J Clin Pract 17: 817-818, 2014.

2. Turgut B, Kurt J, Catak O and Demir T: Phthriasis palpebrarum mimicking lid eczema and blepharitis. J Ophthalmol 2009: 803951, 2009.

3. Lacarrubba F and Micali G: The not-so-naked eye: Phthiriasis palpebrarum. Am J Med 126: 960-961, 2013.

4. Anane S, Malek I, Kamoun R and Chtourou O: Phthiriasis palpebrarum: Diagnosis and treatment. J Fr Ophtalmol 36: 815-819, 2013.

5. Anderson AL and Chaney E: Pubic lice (Pthirus pubis): History, biology and treatment vs. knowledge and beliefs of US college students. Int J Environ Res Public Health 6: 592-600, 2009.

6. Ryan MF: Phthiriasis palpebrarum infection: A concern for child abuse. J Emerg Med 46: e159-e162, 2014.

7. Yi JW, Li L and Luo da W: Phthiriasis palpebrarum misdiagnosed as allergic blepharoconjunctivitis in a 6-year-old girl. Niger J Clin Pract 17: 537-539, 2014.

8. Charfi F, Ben Zina Z, Maazoun M, Kharrat W, Sellami D, Makni F, Ayadi A and Feki J: Phthiriasis pubis palpebrarum in children. Diagnosis and treatment. J Fr Ophtalmol 28: 765-768, 2005 (In French).

9. Varela JA, Otero L, Espinosa E, Sánchez C, Junquera ML and Vázquez F: Pthirus pubis in a sexually transmitted diseases unit: A study of 14 years. Sex Transm Dis 30: 292-296, 2003.

10. Workowski KA and Berman SM: Sexually transmitted diseases treatment guidelines, 2006. MMWR Recomm Rep 55: 79-80, 2006.

11. Pinckney J II, Cole P, Vadapalli SP and Rosen T: Phthiriasis palpebrarum: A common culprit with uncommon presentation. Dermatol Online J 14: 7, 2008
12. Couch JM, Green WR, Hirst LW and de la Cruz ZC: Diagnosing and treating Pthirus pubis palpebrarum. Surv Ophthalmol 26: 219-225, 1982.

13. Manjunatha NP, Jayamanne GR, Desai SP, Moss TR, Lalik J and Woodland A: Pediculosis pubis: Presentation to ophthalmologist as pthriasis palpebrarum associated with corneal epithelial keratitis. Int J STD AIDS 17: 424-426, 2006.

14. Rundle PA and Hunghes DS: Pthirus pubis infestation of the eyelids. Br J Ophthalmol 77: 815-816, 1993.

15. Kincaid MC: Pthirus pubis infestation of the lashes. JAMA 249: $590,1983$.

16. Panadero-Fontán R and Otranto D: Arthropods affecting the human eye. Vet Parasitol 208: 84-93, 2015.

17. de Pinho Paes Barreto R, Biancardi AL and Salgueiro MJ: Chronic conjunctivitis related to phthiriasis palpebrarum. Int Ophthalmol 32: 467-469, 2012.

18. Dağdelen S, Aykan U and Cetinkaya K: Phthriasis palpebrarum can resemble tick larva infestation in an eyelid. J AAPOS 17: 440-442, 2013.

19. Karabela Y, Yardimci G, Yildirim I, Atalay E and Karabela SN: Treatment of Phthiriasis Palpebrarum and crab louse: Petrolatum jelly and 1\% Permethrin shampoo. Case Rep Med 2015: 287906 , 2015.

20. Sundu C, Dinç E, Kurtuluş UC and Yıldırım Ö: Common blepharitis related to Phthiriasis Palpebrarum: Argon laser phototherapy. Turkiye Parazitol Derg 39: 252-254, 2015.

21. Elston DM: Drugs used in the treatment of pediculosis. J Drugs Dermatol 4: 207-211, 2005 .

22. Jiang J, Shen T and Hong CY: A peculiar case of eye pruritus: Phthiriasis palpebrarum initially misdiagnosed as common blepharitis. Int J Ophthalmol 4: 676-677, 2011.

23. Ngai JW, Yuen HK and Li FC: An unusual case of eye itchiness. Hong Kong Med J 14: 414-415, 2008.

24. Kumar N, Dong B and Jenkins C: Pubic lice effectively treated with Pilogel. Eye (Lond) 17: 538-539, 2003.

25. Thappa DM, Karthikeyan K and Jeevankumar B: Phthiriasis palpebrarum. Postgrad Med J 79: 102, 2003.

26. Reddy SC: Phthiriasis palpebrarum. Indian J Ophthalmol 28: 39-41, 1980. 